\title{
SÍTIO FURNA DO ESTRAGO, PE Práticas Funerárias e Marcadores de Identidades Coletivas
}

\author{
ARCHAEOLOGICAL SITE FURNA DO ESTRAGO, PE \\ Funerary Practices and Markers of Collective Identities
}

\author{
Viviane Maria Cavalcanti de Castro ${ }^{1}$ \\ vivianemcc@gmail.com
}

\section{RESUMO}

Este artigo apresenta o estudo dos marcadores de identidades coletivas na materialidade das estruturas funerárias do sítio pré-histórico Furna do Estrago, localizado no Município do Brejo da Madre de Deus, Pernambuco, Brasil. Como resultado, registrou-se: presença de colares e uso de envoltório em fibra vegetal, indicadores de representação material de identidades coletivas - elementos recorrentes na maioria dos indivíduos sepultados - e a existência de elementos indicadores de identidades vinculados à idade dos indivíduos. No sítio Furna do Estrago o contexto funerário apresentou marcadores de identidades coletivas, associados à idade, forma de deposição do corpo e representados na cultura material.

Palavras-chave: Contexto Funerário, Identidades, Brejo da Madre de Deus

\footnotetext{
${ }^{1}$ Departamento de Arqueologia, UFPE.
} 


\begin{abstract}
This article presents the study of collective identity markers in the materiality of the funerary structures of the prehistoric site Furna do Estrago, located in the municipality of Brejo da Madre de Deus, Pernambuco, Brazil. As a result, there was: the presence of collars and the use of wrapping in vegetal fiber, indicators of material representation of collective identities - recurrent elements in the majority of buried individuals - and the existence of indicators of identity linked to the age of individuals. In the Furna do Estrago site, the funerary context presented collective identity markers, associated to age, body deposition and represented in material culture.
\end{abstract}

Keywords: Funerary Context, Identities, Brejo da Madre de Deus

\title{
ANTECEDENTES
}

O contexto funerário é um dos espaços onde identidades foram construídas e materializadas nos elementos presentes nos sepultamentos. Os traços ou os marcadores de identidades (quer sejam de sexo, de idade, de status, dentre outros) estão representados materialmente nas estruturas funerárias. A cultura material, nos contextos funerários, pode proporcionar um ponto de vista sobre as identidades com base na identificação das semelhanças e diferenças (Silva, 2005; Wooward, 2005). A diferença é o que demarca uma identidade de outra.

Defendemos que existe uma relação entre identidades e a cultura material e para trabalhar esta relação argumentamos que a identidade, no campo da Arqueologia é materializada e coletiva, pois trabalha com os vestígios dos grupos. Contudo, devemos ressaltar que não estamos negando o indivíduo ativo e os vestígios de suas identidades. Porém, para a proposta que apresentamos neste trabalho, optamos por discutir as identidades coletivas. 
Os indivíduos vivem em grupos e integram as identidades coletivas e individuais, reconhecendo-se em seus semelhantes. De acordo com Vidal e Silva (2000), esse processo interno de identificação servia, ao mesmo tempo, para se reconhecer como diferenciado de outros grupos e no interior da própria sociedade. Mediante este processo também imprimiam, em seus objetos, as marcas de suas identidades.

Portanto, nossa argumentação parte da hipótese de que as estruturas funerárias pré-históricas apresentam elementos de cultura material, e de características biológicas do indivíduo sepultado, que podem ser considerados como marcadores de identidades coletivas. As estruturas funerárias são formadas, portanto, pela tríade componencial: corpo, cova e acompanhamentos funerários (Silva, 2014).

Uma estrutura funerária é parte material e vestigial de um ritual ou de um conjunto de rituais. A decisão de como sepultar os adultos e/ou as crianças de um grupo não é acidental, seguem regras, comportamentos formalizados e vinculados, na maioria das vezes, ao sexo, à idade, ao parentesco, à posição social (Binford, 1971), à atividade que o indivíduo exercia; mas também, as decisões de como proceder nos sepultamentos podem estar de acordo com as interpretações simbólicas e cosmológicas dos grupos.

De acordo com Silva (2014: 50) "Um sepultamento é parte de um funeral e um funeral é parte de um conjunto de rituais pelos quais os vivos relacionam-se com a 
morte." Um ritual funerário apresenta persistência temporal nas regras e nos elementos constituintes. A realização de um sepultamento é uma ocasião especial que serve para o grupo reafirmar suas crenças e valores. Por conseguinte, são ocasiões que servem para transmitir conhecimentos, memória e identidades.

\section{IDENTIDADES E PRÁTICAS FUNERÁRIAS}

A noção de identidade tem sido objeto de investigação de várias disciplinas das ciências humanas e sociais. A "noção de identidade não está restrita a um campo específico e não é exclusiva de nenhuma disciplina. É utilizada de diferentes maneiras. Identidade pode se referir a sexo, religião, profissão, gênero ou status" (Castro, 2008).

O conceito tradicional, utilizado no início do século XX, descrevia a identidade como um elemento estável, duradouro e preexistente. Neste período, a Arqueologia entendia as identidades como culturas e essas significavam os grupos étnicos. Já no início do século XXI as identidades passam a ser consideradas como construções sociais, e são múltiplas, dinâmicas, e não apenas construídas tendo por base as semelhanças, mas, também e, especialmente, pela relação entre semelhanças e diferenças. As identidades mudam, mas também existem elementos considerados mais duradouros como os existentes nos rituais.

As identidades também apresentam elementos materiais. Para Woodward (2005) a identidade, como representação, se expressa nos objetos. Os objetos funcionam 
como significante da diferença e podem ser utilizados para afirmar identidades. Em sua opinião há uma associação entre os objetos e a identidade.

As identidades podem ser construídas pelo que é visível, pelos artefatos e estruturas. Conforme Jorge (2002) a arqueologia pré-histórica constrói identidades através da interpretação de objetos e monumentos e das regularidades identificadas nos vestígios.

Assim, argumentamos que os próprios elementos presentes na estrutura funerária podem ser interpretados como materializações dessas representações de identidades.

Quando tratamos de vestígios funerários, mesmo que pré-históricos, estamos no campo do ritual. O contexto funerário é resultado de ações sociais realizadas durante o ritual funerário. Os rituais também são entendidos como ações duradouras e repetitivas, menos suscetíveis a mudanças. É uma das maneiras de reforçar a cultura e os valores sociais, pois, como nos recorda Martin (2005: 307), o “(...) homem é também tradicionalmente conservador no culto aos seus mortos e a mudança das culturas reflete-se mais lentamente nos rituais e nos costumes funerários do que na evolução da vida cotidiana". É através da realização do ritual funerário que o grupo comunica suas escolhas e preferências, transmitidas através de suas tradições, pois o contexto funerário é também um espaço onde identidades foram construídas e/ou representadas. Nesse sentido, transmite uma parte de sua 
memória grupal, coletiva, manifestada e materializada no sepultamento. Assim, as práticas funerárias possuem elementos de comunicação e de representação do grupo.

A estrutura funerária é parte de um contexto que salvaguarda a memória social do morto, o qual, após a morte, preservou o seu status, o seu lugar, as suas identidades, como também sua representação, sejam coletivas e individuais. Contudo, a duração da memória relaciona-se com a duração do grupo. A reconstrução de um ritual do passado não reproduz este passado. Da mesma forma que o presente também não é capaz de eliminar as experiências do passado (Santos, 2003).

\section{O SÍTIO FURNA DO ESTRAGO}

O sítio Furna do Estrago é um abrigo sob-rocha granítica e está localizado no sopé da Serra da Boa Vista a uma altitude de 650 metros, e próximo à sede do município do Brejo da Madre de Deus, Pernambuco, Brasil (Figura 1). O abrigo possui abertura de 19 metros, voltada para nordeste, altura de 4,80 metros e profundidade de 8,80 metros (Figuras 2 e 3 ). 
Localizaçăo do sitio arqueológico Furna do Estrago

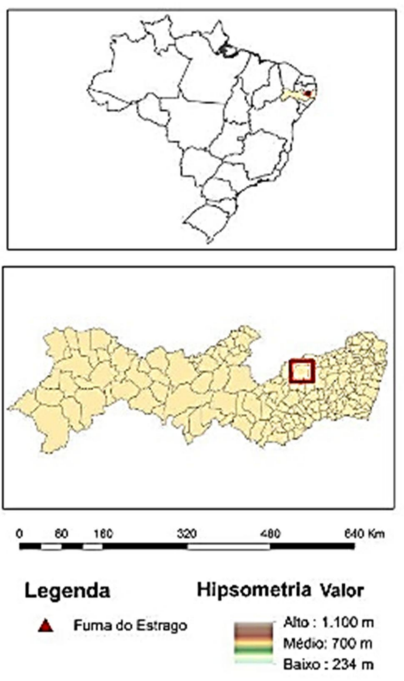

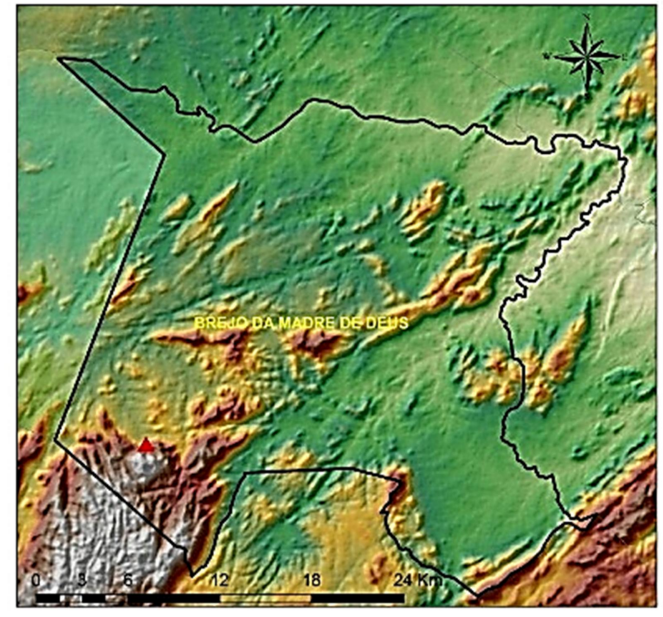

Sisterna de Ccordenadas de Projeção
Prejeço:Transwerse de Mercato Datum: SIRGAS 2000
Zona: $24 S$
Figura 1. Mapa de localização do sítio Furna do Estrago no município do Brejo da Madre de Deus.

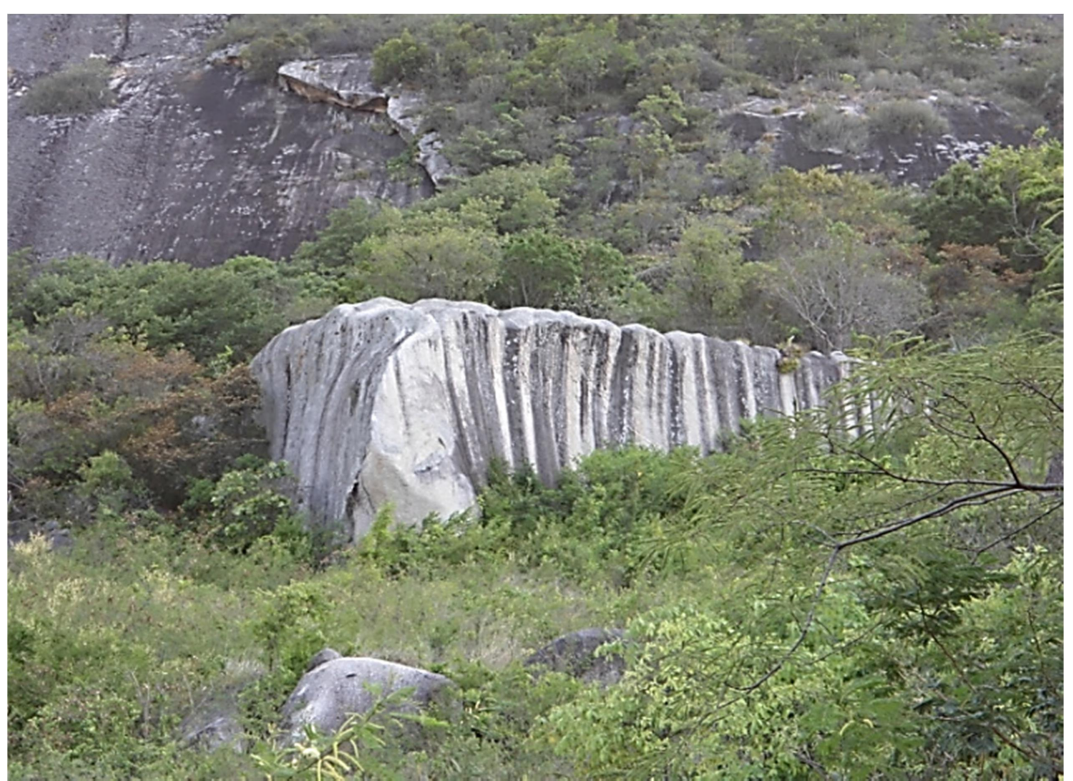

Figura 2. Sítio Furna do Estrago. Vista geral. 


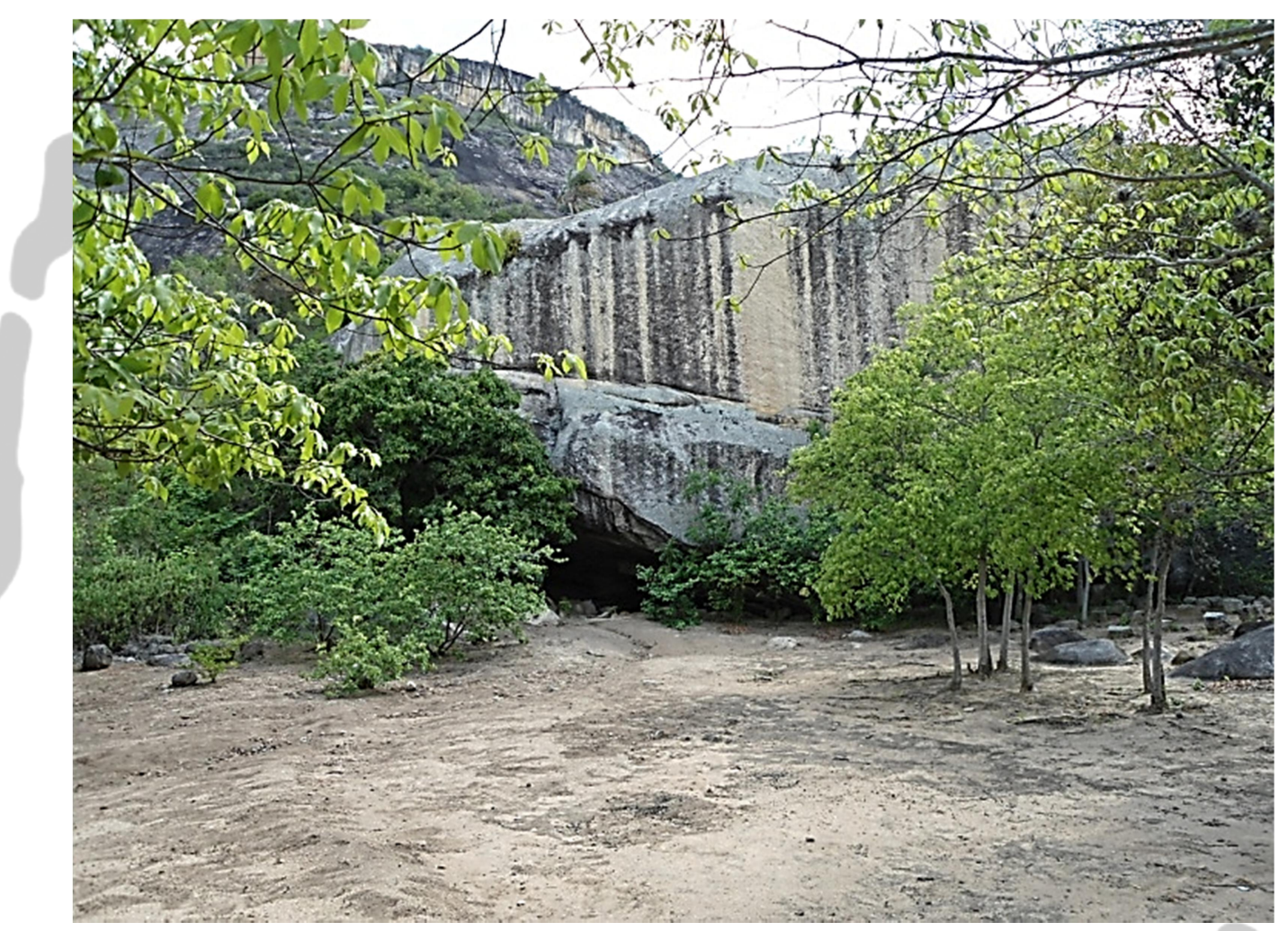

Figura 3. Sítio Furna do Estrago.

As atividades arqueológicas que geraram o acervo de materiais ocorreram durante os anos de 1982, 1983, 1987, 1994 e 1996 e originaram estudos nas áreas de Arqueologia, Antropologia Biológica, Bioarqueologia, Botânica, Geologia e Zoologia. Em relação aos estudos direcionados para os sepultamentos e/ou sobre os esqueletos: Mello e Alvim e Mendonça de Souza (1983-1984), Lima (1984a, 1984b, 1985a, 1985b, 2001), Mendonça de Souza (1992, 1995), Carvalho (1992, 
1995), Mendonça de Souza, Mello e Alvim (1992), Duarte (1994), Rodrigues (1997), Carvalho et al. (2007), Menezes (2006), Castro (2009), Lima (2012), Schmitz et al. (2012), Alencar (2013, 2015), Oliveira (2014, 2017), Silva (2016).

Os estudos realizados com os vestígios e materiais ósseos da Furna do Estrago caracterizaram biológica e culturalmente a população humana sepultada neste sítio e foram de suma importância para atender ao objetivo de identificar os elementos de identidades.

\section{MATERIAL E MÉTODOS}

\section{Coleta e tratamento dos dados}

Operacionalmente, foi realizado o levantamento da documentação primária e secundária, relacionada com o sítio Furna do Estrago. A partir da documentação de campo, existente no Laboratório e Museu de Arqueologia da Universidade Católica de Pernambuco (relatórios, fichas de campo, fotografias, plantas e desenhos) foi registrada as informações provenientes de cada sepultamento (cultura material associada e da sepultura). Assim como foram consultadas as publicações referentes ao sítio.

Os dados, de setenta e três (73) indivíduos, foram analisados de acordo com variáveis biológicas e culturais, das quais utilizamos as categorias relacionadas ao corpo, incluindo o sexo e a idade, tratamento dos ossos, posição do corpo, tipo de sepultamento, elementos constituintes da cova ou sepultura, acompanhamentos 
funerários, uso de envoltórios e cronologia das ocupações. Para a identificação dos elementos ou marcadores de identidades foi preciso distinguir, na estrutura funerária, as recorrências e as diferenças em cada sepultamento, e realizar comparações entre os elementos.

\section{Procedimentos utilizados na análise das estruturas funerárias}

Nas práticas funerárias é possível reconhecer os elementos ou marcadores de identidades na recorrência e na representatividade material qualitativa e quantitativa das categorias analisadas. Para propor elementos ou marcadores de identidades foi preciso, na estrutura funerária:

1. Verificar as recorrências e as diferenças encontradas nas variáveis analisadas;

2. Realizar associações entre as variáveis mais recorrentes;

3. Propor, hipoteticamente, a partir dos resultados das associações quais seriam os marcadores de identidades coletivas.

O primeiro procedimento da análise foi dar um tratamento uniforme e sistemático aos sepultamentos por meio do banco de dados. Em seguida, identificamos, por meio da estatística descritiva, as recorrências e as diferenças presentes nas unidades funerárias do sítio. A partir da identificação das variáveis de análise, realizamos associações. 


\section{Variáveis culturais e biológicas}

As variáveis biológicas foram o sexo e a idade (faixa etária). As variáveis culturais incluem os dados relativos às características das sepulturas e do corpo (a preparação do corpo, a destinação do corpo, a posição do corpo e dos membros). Também estão incluídos os elementos materiais associados ao sepultamento ou ao ritual (Silva, 2005/2006). São itens que passaram a fazer parte do contexto funerário, podendo ter sido, anteriormente, do próprio morto, da sua família ou preparados especialmente para o momento do ritual funerário. São exemplos os instrumentos (de trabalho, musicais), adornos, vasilhas cerâmicas, corantes, vestígios vegetais e da fauna. Pode-se até incluir outro grupo de materiais, as oferendas, utilizadas durante o ritual funerário, mas de difícil verificação no registro arqueológico.

Como afirma Binford (1971) os acompanhamentos são importantes reveladores de atividades econômicas, como também de autoridade e status. Por sua vez, Tainter (1978) propõe observar se há ausência de determinado material relacionado à idade e ao sexo. Portanto, os tipos de materiais, as quantidades e suas características relacionadas à idade e ao sexo dos indivíduos enterrados podem ser marcadores, também, de identidades coletivas e/ou individuais.

Para avaliar uma possível variação ao longo do tempo utilizamos os critérios cronológicos estabelecidos por Lima (1985a, 2001), apesar de que não há datação absoluta para todos os indivíduos e de que o período compreendido entre os 
sepultamentos datados colocam o cemitério em uso por aproximadamente 250 anos.

\section{Estatística descritiva}

A estatística descritiva aplica técnicas para descrever e sumarizar um conjunto de dados. O trabalho estatístico foi realizado utilizando o programa Minitab. As bases de dados referentes ao sítio estudado foram descritas utilizando as frequências de ocorrência (em porcentagem) de cada categoria, dentro da variável (no caso das variáveis categóricas), ou a frequência de ocorrência dos valores merísticos (para variáveis numéricas). A moda foi a medida de tendência central usada para descrever as ocorrências mais recorrentes. Para a descrição de cada variável, a unidade de análise foi o esqueleto, ou o indivíduo sepultado.

A grande maioria das informações das bases de dados é categórica, e a alta proporção de dados inexistentes, para algumas variáveis, impede que elas sejam representativas da amostra. Nestes casos, não foi feita nenhuma análise mais profunda da variável e aguarda-se a coleta de mais dados para análises e conclusões futuras.

Em alguns casos, fez-se uma revisão do número de categorias em uma variável para permitir a análise estatística, agrupando-se categorias similares, de forma a reduzir o número de variações. Um exemplo é a faixa etária: na base de dados original, há categorias como "adulto", "adulto jovem" e "adulto indeterminado", 
que foram agrupadas em uma única categoria, "adulto". Outro exemplo é o tipo de adorno recuperado com o esqueleto. Apesar de perder-se, neste caso, a peculiaridade de cada um destes artefatos, a redução das categorias a termos mais gerais (por exemplo, "colar", independente do material utilizado) permite a visualização da riqueza e diversidade de adornos e auxilia na análise da amostra. Este método de organização de dados é coerente com o sugerido por Shennan (1997), para análise de material arqueológico.

\section{RESULTADOS}

No sítio Furna do Estrago foram resgatados mais de oitenta (80) indivíduos que apresentavam boa conservação dos ossos. Contudo, avaliando a falta de dados sobre alguns sepultamentos, consideramos, em nossas análises, setenta e três (73) indivíduos.

De acordo com Lima (2001) os sepultamentos se encontravam organizados em conjuntos, e sobrepostos. Em alguns locais ocorreu uma recolocação de esqueletos, para dar lugar a novos sepultamentos. Nestes, a deposição não foi resultado de sepultamentos secundários, e sim, de uma "arrumação" de antigos esqueletos. Como resultado desse tipo de ação, muitos se encontravam em parte destruídos, mutilados e friáveis; em alguns casos, apenas a cabeça foi resgatada. Isto explica também a presença de ossos descontextualizados nos níveis superiores do abrigo. 
De acordo com os parâmetros profundidade das fossas e registro estratigráfico foi definido, hipoteticamente, para a ocupação do sítio como cemitério, que a profundidade em que se encontravam os esqueletos seria um indicador cronológico. Três níveis de sepultamentos foram estabelecidos por Lima (1985b, 2001): ocupação antiga, com os sepultamentos posicionados abaixo de $80 \mathrm{~cm}$ de profundidade (23\%); a ocupação intermediária, com fossas funerárias entre 50 e $80 \mathrm{~cm}$ de profundidade (51\%), e a ocupação recente, com os posicionados a até 50 $\mathrm{cm}$ de profundidade (26\%) O posicionamento cronológico da ocupação do sítio como cemitério ficou compreendido entre 1000 e 2000 BP (Lima, 2001). Uma datação de $1040 \pm 50$ foi usada inicialmente como referência aos sepultamentos, que seriam mais antigos do que esta data.

O posicionamento cronológico estabelecido por Lima $(1985 \mathrm{~b}, 2001)$ foi parcialmente evidenciado com outras três datações (Quadro 1): $1860 \pm 50 \mathrm{BP}$ (Beta 145954) para o sepultamento FE 18 (ocupação antiga), $1730 \pm 70$ BP (Beta 149749) para o sepultamento FE 87.23, e $1610 \pm 70$ BP (Beta 145955) para o sepultamento FE 45 (ocupação recente). Em relação ao número de indivíduos enterrados em cada ocupação, foi maior na ocupação intermediária. 


\begin{tabular}{|l|l|l|l|}
\hline Datação C 14 & Laboratório & Material datado & Ocupação \\
\hline $1860 \pm 50 \mathrm{BP}$ & Beta 145954 & Esqueleto FE-18 & Antiga \\
\hline $1730 \pm 70 \mathrm{BP}$ & Beta 149749 & Esqueleto FE-87.23 & Intermediária \\
\hline $1610 \pm 70 \mathrm{BP}$ & Beta 145955 & Esqueleto FE-45 & Recente \\
\hline
\end{tabular}

Quadro 1. Datações sítio Furna do Estrago. Fonte: Lima (1985a, 2001).

Todos os sepultamentos da Furna do Estrago são simples, apenas um indivíduo por sepultura. Em relação à determinação do sexo dos indivíduos, as proporções encontradas foram: $15,1 \%$ do sexo feminino (correspondendo a 11 indivíduos); $35,6 \%$ do sexo masculino (correspondendo a 26 indivíduos); em 49,3\% dos casos não foi possível a identificação do sexo (correspondendo a 36 indivíduos) A alta proporção de indivíduos sem a determinação do sexo impediu que esta variável fosse utilizada em testes de múltiplas variáveis. Do total dos indivíduos indeterminados quanto ao sexo, vinte (20) são lactentes e crianças, três (3) são adolescentes. Os treze (13) indivíduos restantes são adultos.

$\mathrm{Na}$ variável idade há sete categorias ${ }^{2}$ : lactente (0-2a); criança (>2-12a); adolescente (>12-20a); adulto jovem ( $>20-35 \mathrm{a})$; adulto ( $>35-50 \mathrm{a})$; idoso ( $>50 \mathrm{a})$ e indeterminado (quando não foi possível determinar). Na Furna do Estrago, os indivíduos sepultados estavam distribuídos, por idade, como visto na Tabela 1.

\footnotetext{
${ }^{2}$ Os subadultos se encontram na faixa etária de feto até 20 anos (White, Black e Folkens, 2012). Contudo, em nosso trabalho dividimos os subadultos em lactente, criança e adolescente com a finalidade de identificar se haveria elementos materiais nos sepultamentos específicos para cada faixa etária.
} 


\begin{tabular}{|l|c|c|}
\hline \multicolumn{1}{|c|}{ Faixa etária } & $\begin{array}{c}\text { Total de } \\
\text { indivíduos }\end{array}$ & $\begin{array}{c}\text { Proporção de } \\
\text { indivíduos (\%) }\end{array}$ \\
\hline Lactente & 8 & 10,96 \\
\hline Criança & 12 & 16,44 \\
\hline Adolescente & 3 & 4,11 \\
\hline Adulto Jovem & 18 & 24,66 \\
\hline Adulto & 27 & 36,99 \\
\hline Idoso & 4 & 5,48 \\
\hline Indeterminado & 1 & 1,36 \\
\hline
\end{tabular}

Tabela 1. Distribuição por faixa etária dos indivíduos enterrados na Furna do Estrago.

Neste sítio, a maioria dos indivíduos enterrados era adulta; somando-se adultos jovens e adultos, $61,65 \%$ dos sepultamentos encontram-se nestas categorias (Figura 4).

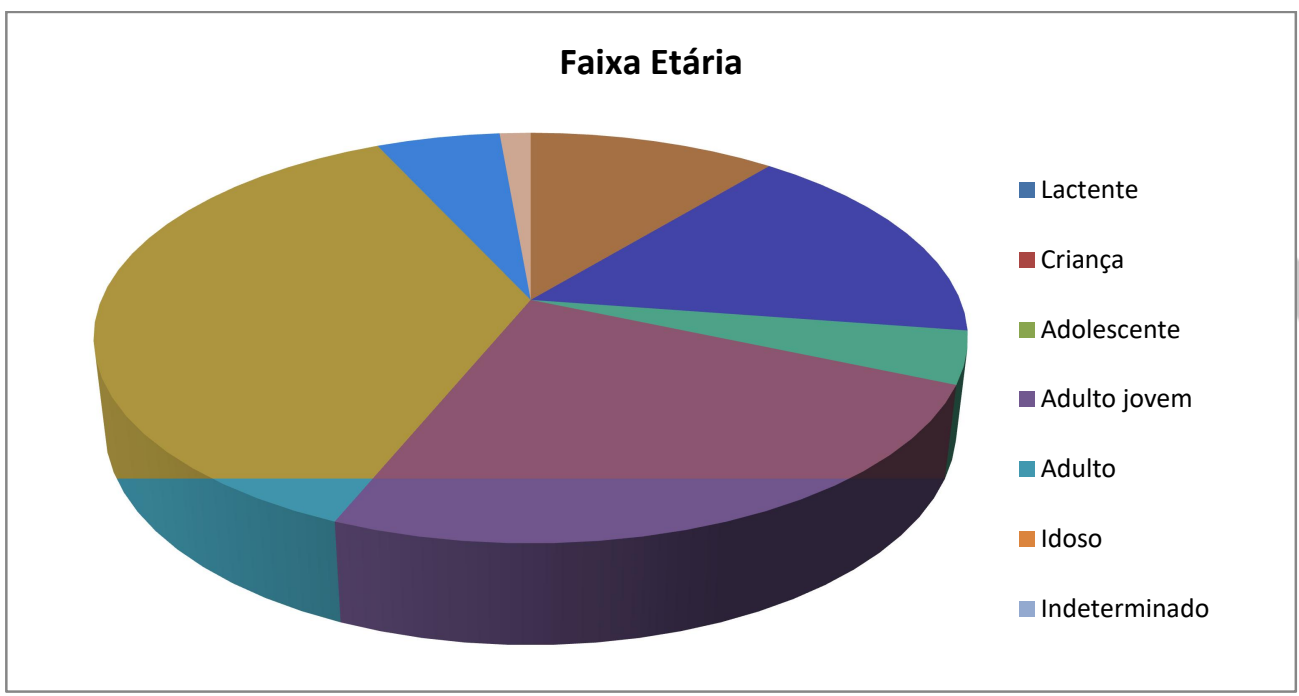

Figura 4. Distribuição da faixa etária dos indivíduos enterrados no sítio Furna do Estrago. 
Verificamos que, em todas as idades, o sepultamento primário foi predominante. São "primários" (sessenta sepultamentos, $82,19 \%$ da amostra); "secundários" (três sepultamentos, 4,11\%); e "restos de ossos" (sete sepultamentos, 9,59\%); três sepultamentos, ou $4,11 \%$ da amostra, foram classificados como "indeterminados" (Figura 5). Os restos de ossos correspondem a sepultamentos que foram perturbados e dos quais não é possível definir o tipo de sepultura. Todos os subadultos (de 0 a 20 anos) estão em sepultamentos primários. Os três sepultamentos secundários pertenciam a um idoso e a dois adultos. Desta forma, há recorrência do sepultamento primário em todas as idades e nas três ocupações.

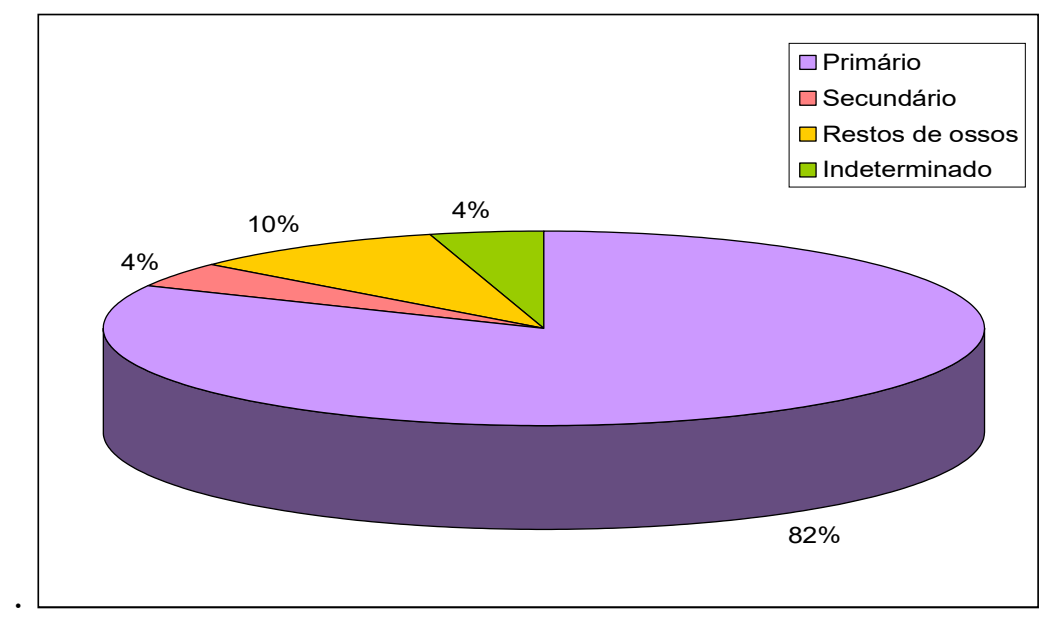

Figura 5. Tipos de sepultamento no sítio Furna do Estrago.

No sepultamento secundário de um idoso da ocupação antiga não há adornos nem envoltório. Na ocupação intermediária o idoso passa a ter mais objetos em sua 
sepultura. Isto poderia ser indicador de uma mudança nos costumes sociais em relação aos idosos. Os resultados da estatística descritiva indicam um aumento no número de adornos na ocupação intermediária, em todas as idades.

A deposição do corpo está relacionada com a idade. Esta variável descreve a posição do corpo na sepultura e tem as seguintes categorias: "decúbito dorsal" (treze indivíduos, 17,81\% da amostra); "decúbito lateral" (cinco indivíduos, 6,85\%); "decúbito lateral direito" (dezesseis indivíduos, 21,92\%); e "decúbito lateral esquerdo" (quinze indivíduos, 20,55\%). Para 24 esqueletos, ou 32,88\% da amostra, a posição do corpo não foi determinada. Contudo, reduzindo as categorias para decúbito dorsal, decúbito lateral e indeterminado, observa-se que a posição predominante para os adultos e adolescentes foi o decúbito lateral, tanto direito como esquerdo, não havendo relação da lateralidade com o sexo. Em relação às crianças, a maioria (12 indivíduos), distribuídas nas três ocupações, foi depositada em decúbito dorsal. Porém, quatro (4) estavam em decúbito lateral e em quatro (4) não foi possível determinar a posição do corpo na sepultura.

Este resultado, apesar do número de indeterminados, é um forte indicador de identidades baseadas na idade dos indivíduos. Adultos e crianças foram enterrados em posição diferenciada, pois representam identidades distintas.

Foi verificada a frequência das posições dos corpos nas três ocupações, através de um gráfico de cluster (Figura 6). Porém, os resultados não indicam variação nas 
três ocupações. Isto pode significar que a posição do corpo manteve-se regular ao longo dos três períodos de ocupação em função da idade dos indivíduos.

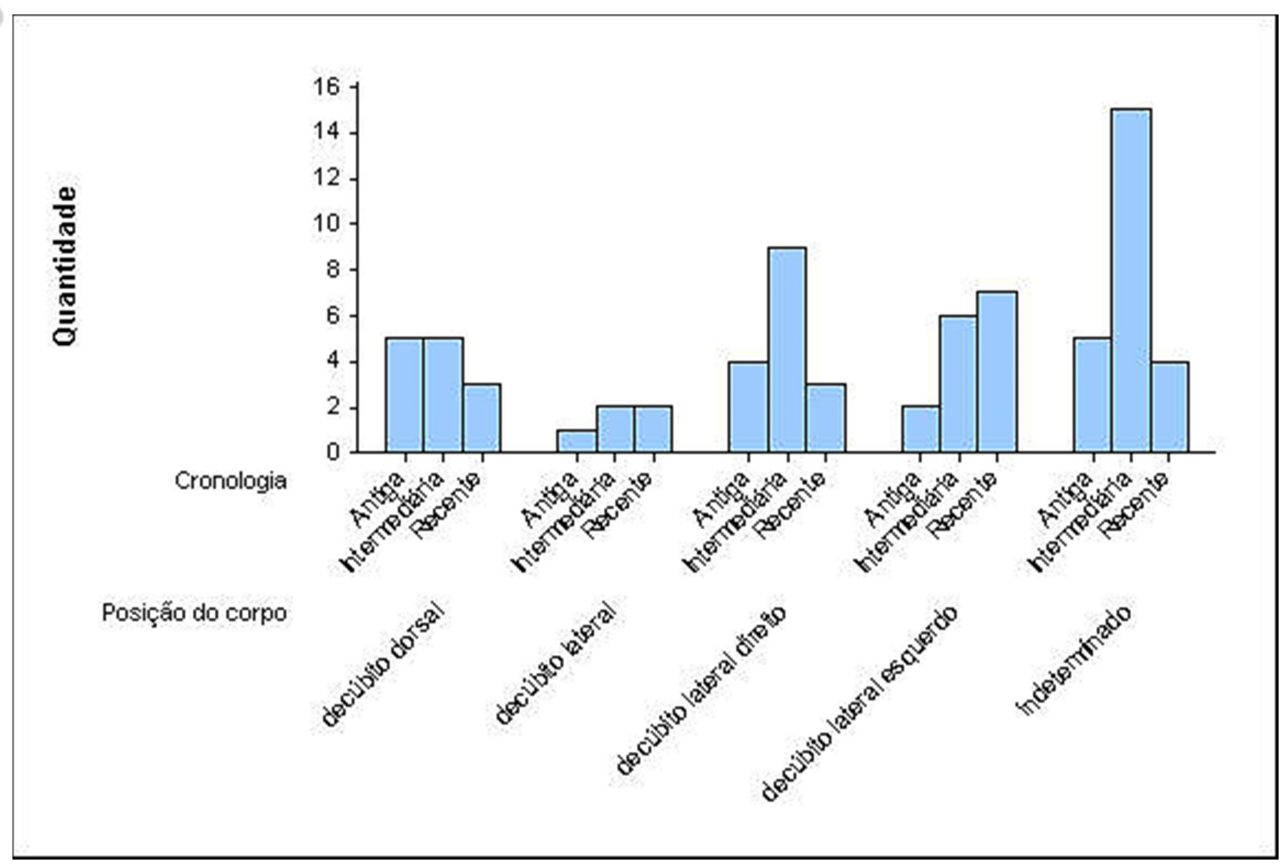

Figura 6. Frequência das posições dos corpos do sítio Furna do Estrago, nas três ocupações.

Em relação à presença de acompanhamentos funerários no sítio Furna do Estrago, foram encontradas contas de colares e pingentes em 41 sepulturas (ou 56,9\% do total no sítio), de adultos e crianças. Estes adornos são descritos em nove categorias de matéria-prima. A distribuição dos tipos de adornos pode ser vista na Tabela 2 e na Figura 7. 


\begin{tabular}{|l|c|}
\hline \multicolumn{1}{|c|}{ Tipo de adorno } & Quantidade \\
\hline Colar de conchas & 2 \\
\hline Colar de ossos & 23 \\
\hline Colar de pedra & 5 \\
\hline Colar de dentes & 1 \\
\hline Colar de osso e dente & 1 \\
\hline Colar de osso e concha & 3 \\
\hline Colar de osso e pedra & 1 \\
\hline Colar de sementes & 3 \\
\hline Colar de osso/concha/pedra & 3 \\
\hline
\end{tabular}

Tabela 2. Distribuição dos adornos de acordo com o tipo de matéria-prima.

Agrupando os adornos em categorias mais gerais, como colares de contas ou pingentes, verifica-se que a maioria é representada por colares, feitos de materiais diversos, como: conchas, ossos, sementes e pedras (Figura 7), enquanto os pingentes foram confeccionados de ossos, dentes ou pedras.

A frequência predominante de adornos nos indivíduos adultos foi de colares de contas de ossos (Figura 8); em segundo lugar, colares de pedras e de conchas. Tanto no sexo masculino como feminino a predominância corresponde aos colares feitos de ossos. Isto também ocorre nos adultos de sexo indeterminado. Os pingentes apresentaram número reduzido e, em sua maioria, faziam parte do colar. 


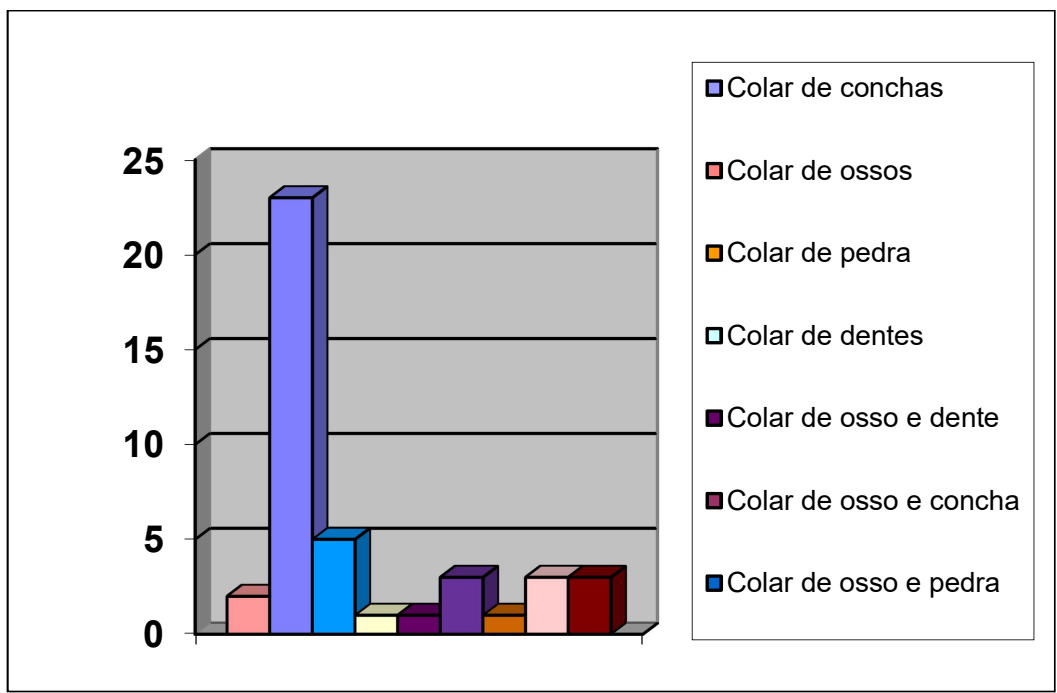

Figura 7. Frequência de tipos de matéria-prima dos adornos do sítio Furna do Estrago.

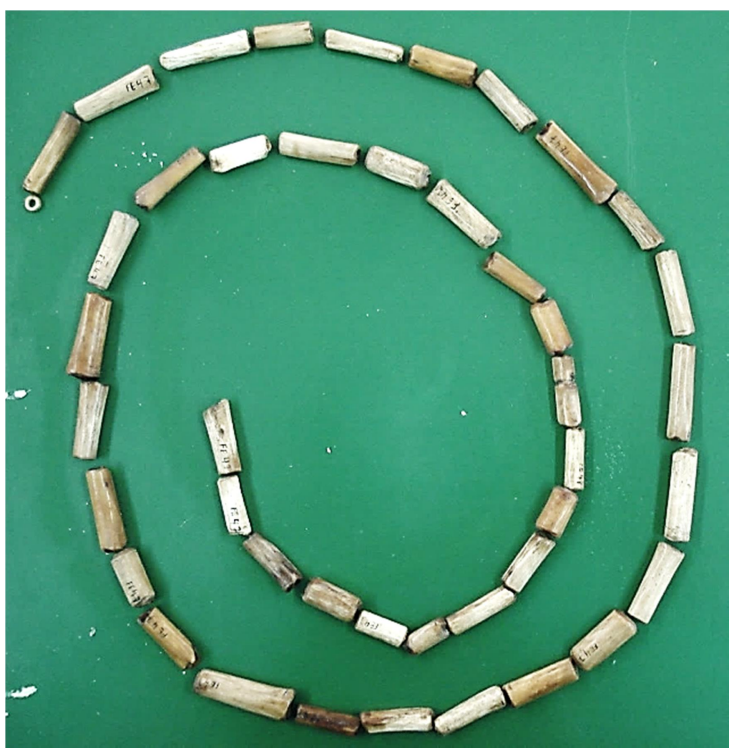

Figura 8. Colar de ossos. Sítio Furna do Estrago. 
Nas crianças também houve predominância de adornos de ossos. A quantidade de adornos por criança também foi recorrente: predomínio de apenas um adorno por sepultura. Porém, na ocupação recente constatou-se um aumento no número de crianças com adornos: três crianças com adorno e uma não o possuía.

Sementes de gindiroba (Fevillea trilobata) e de pequi (Caryocar coriaceum Wittm.) também foram utilizadas como colares e estão presentes em apenas três indivíduos adultos da ocupação intermediária (Menezes, 2006). Além de sementes, foram identificados cordéis de caroá (Neoglaziovia variegata Mez.) associados a quatro indivíduos (três adultos e uma criança). De acordo com Lima (2001), os cordéis estariam relacionados aos colares, talvez com função de cordão para as contas.

Algum tipo de envoltório de fibra vegetal (Figuras 9 e 10) foi encontrado em 42 indivíduos (57,53\% dos sepultamentos), que foram categorizados como: "esteira" (treze, 17,8\% do total); "palha" (quatorze, 19,18\%); "trançado" (um, 1,36\% da amostra); "esteira e palha" (nove, 12,39\%); "esteira e trançado" (três, 4,11\% das amostras); "palha e trançado" (um, 1,36\% da amostra); e "esteira, palha e trançado" (um, 1,36\% da amostra). 


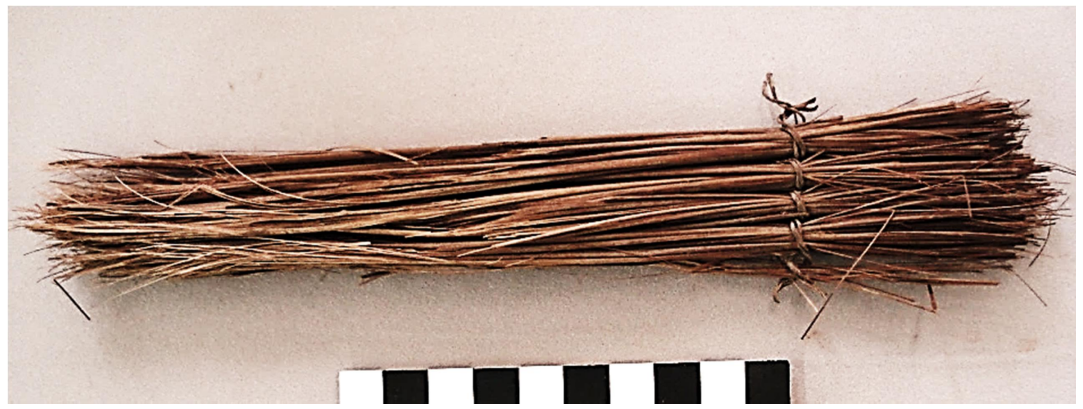

Figura 9. Fragmento de fibra vegetal. Sítio Furna do Estrago.

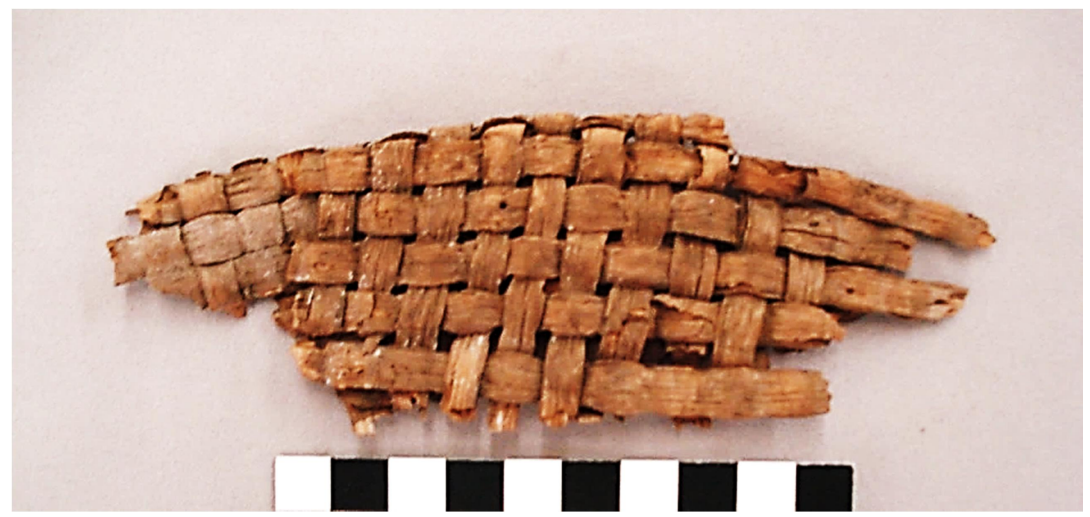

Figura 10. Fragmento de fibra vegetal trançada. Sítio Furna do Estrago.

A natureza da variável "tipo de envoltório" não permitiu a análise por testes de significância, mas pode-se visualizar a frequência de uso dos materiais entre as ocupações através de um gráfico de cluster (Figura 11). Nos indivíduos adultos as esteiras e a palha foram utilizadas separadamente e também em conjunto; nas crianças foi constatado o uso predominante de esteiras, seguido da palha e do trançado. Os trançados apresentam as seguintes técnicas: trançado torcido vertical 
e trançado quadricular gradeado compacto. As esteiras foram confeccionadas com folhas de palmeira e as cordinhas com fibras de caroá (Menezes, 2006).

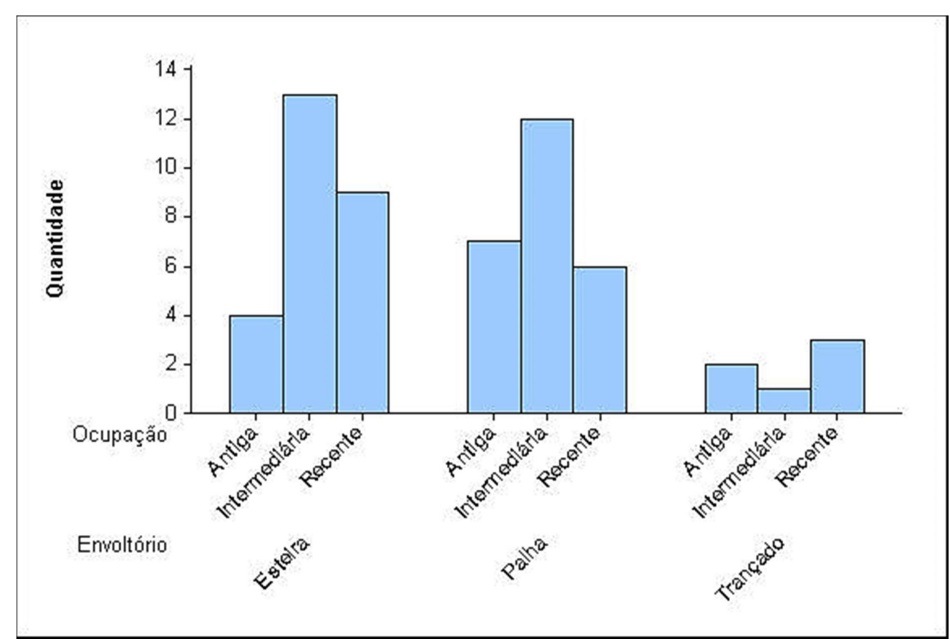

Figura 11. Frequência de uso de diversos materiais como envoltório dos indivíduos enterrados no sítio Furna do Estrago, nas três ocupações.

Observa-se que as esteiras e a palha foram utilizadas durante as três ocupações, porém com maior frequência na intermediária; já o trançado teve um uso mais restrito; provavelmente estava associado a sepultamentos de indivíduos com posição social mais destacada neste grupo. Já a palha e as esteiras estavam associadas à maioria das sepulturas sendo, portanto, um elemento recorrente nas estruturas funerárias deste sítio.

Alguns elementos presentes nas sepulturas não possuem recorrência: instrumentos musicais, instrumentos de osso e instrumentos de madeira. Apenas alguns 
indivíduos foram enterrados com esses objetos. Isto estaria relacionado à má conservação do material ou a uma diferenciação social? Seriam objetos destinados a indivíduos de posição social diferenciada e/ou mais velhos? Dois sepultamentos apresentaram instrumentos musicais. A sepultura de um indivíduo idoso de sexo indeterminado continha duas flautas, enquanto a sepultura de um homem adulto continha uma flauta. Apenas a sepultura de um indivíduo adulto do sexo masculino continha uma espátula de osso de mamífero. Do mesmo modo, duas sepulturas de adultos masculinos continham um tacape, instrumento feito em madeira.

Observamos também que não foi utilizado, como acompanhamento funerário, material cerâmico nem lítico, ou seja, objetos relacionados a atividades de subsistência. Em relação aos elementos constituintes da cova ou sepultura, não foi possível aproveitar estas variáveis na análise, pois não havia dados suficientes sobre tamanho, altura, forma, profundidade ou sobre os materiais utilizados como estrutura ou para demarcar o local das sepulturas.

\section{DISCUSSÃO}

Os resultados das análises realizadas nas estruturas funerárias do sítio Furna do Estrago permitiram identificar algumas identidades coletivas. A posição do corpo, a presença de adornos e de envoltórios de palha foram marcadores de identidades. Nossos resultados podem ser corroborados com algumas informações procedentes 
dos registros etnográficos (Agostinho, 1974; Carneiro da Cunha, 1978; Lukesch, 1976) como também de contextos arqueológicos.

Os registros etnográficos relatam também as diferenças e as variações dentro dos padrões funerários de um grupo em função da idade, sexo, parentesco, organização social e tipo de morte. Os relatos etnográficos e etnohistóricos e os resultados das pesquisas arqueológicas demonstram que o sexo e a idade constituíam as primeiras identidades, recebidas a partir do nascimento.

Com base nos relatos dos cronistas coloniais (D'Evreux, 2002; Lery, 1980; Sousa, 2000; Thevet, 1978) observa-se que, além do sexo e da idade, a posição social do indivíduo também era utilizada para diferenciar as práticas funerárias. Lery (1980: 247), em relação aos procedimentos de sepultamento, enfatiza que os mortos eram enterrados em covas arredondadas e profundas com o corpo amarrado com os braços em torno das pernas; e se o morto era pessoa de importância era enterrado, em sua casa, envolto em sua rede, com seus colares e outros objetos pessoais.

De acordo com Gabriel Soares de Sousa (2000: 289) nas cerimônias realizadas pelos Tupinambá, observava-se diferenças em relação às idades. Em relação à morte do filho do principal da aldeia, descreve que a criança é depositada em uma urna cerâmica e os adultos em cova, envolvidos em uma rede. Em se tratando do sepultamento do principal, descreve que o corpo era preparado com mel e enfeitado com penas e o morto enterrado em sua própria casa, em uma cova 
grande e profunda. $\mathrm{O}$ morto é então enterrado em sua rede de forma a não tocar o chão e colocam como acompanhamentos o arco e flecha, sua espada e o maracá.

André Thevét (1978: 122) descrevendo as cerimônias dos Tupinambá do Rio de Janeiro, relata a devolução dos pertences do morto a fim de que sejam colocados como acompanhamento funerário. Descreve também que o corpo é amarrado com cordas de algodão ou de cascas de certas árvores e enterrado diretamente em uma cova.

Por sua vez D'Evreux (2002: 166 a 167) descreve os costumes funerários de indígenas que habitavam o Maranhão. Relata que enterram o corpo diretamente na terra, com seus objetos pessoais como arco, flechas, machados, assim como a colocação de comida, água e o acendimento de fogueira próximo à sepultura.

Relatos etnográficos atestam que também os acompanhamentos variavam de acordo com a idade e o sexo. Entre os Kayapó, a variabilidade está marcada nos objetos que acompanham o morto e no modo como o ritual é executado. Em Lukesch (1976: 204) há informações sobre as características dos sepultamentos Kayapó. O morto era enterrado com seus adornos e enfeites e outros objetos que possuiu. A quantidade iria variar de acordo com o prestígio pessoal e com a quantidade e o poder dos seus parentes. 
Nos Kamaiurá, o ritual funerário evidencia aspectos da divisão social, com as diferenciações de status, gênero e idade. Na preparação do corpo do morto a diferença do sexo influencia na pintura do corpo e nos adornos que são colocados (Agostinho, 1974). A pintura corporal como marcador de identidade, presente no ritual fúnebre, será perdida com a decomposição biológica. Por sua vez, a pintura feita nos ossos de sepultamentos secundários pode ser também considerada como marcador de identidade, sendo possível sua determinação nos achados arqueológicos.

Deste modo, nos dados etnográficos e etnohistóricos pode ser evidenciada a estreita ligação entre aspectos sociais e sua representação no ritual funerário, que se expressa, em determinados grupos, entre a cultura material e a idade, o sexo ou a posição social do falecido. Isto evidencia que as diferenças entre as pessoas também estão materializadas em seus sepultamentos.

Em nossos resultados para o sítio Furna do Estrago a idade foi fator diferencial na posição do corpo na sepultura. Os indivíduos foram depositados em posições diferentes, na sepultura, em função de suas idades. A maioria das crianças estava em decúbito dorsal e nos adultos a recorrência era ser inumado em decúbito lateral, não importando a lateralidade. Oliveira (2014) estudou as práticas funerárias realizadas nas crianças do sítio Furna do Estrago. Seus resultados colaboram com os nossos. A maioria dos sepultamentos infantis é primário, e prevaleceu a deposição em decúbito dorsal. 
Identificamos os envoltórios de palha, e a presença de adornos como elementos comuns para a Furna do Estrago tanto para os adultos como para as crianças. Isto também foi confirmado em Oliveira (2014) para as crianças da Furna do Estrago. Os envoltórios de fibras vegetais representariam um elemento presente na maioria dos sepultamentos infantis. Nos sepultamentos infantis há recorrência no uso das fibras: crianças recém-nascidas eram colocadas em cesta ou esteira; nas outras crianças há esteira forrando a fossa.

Nas crianças também houve predominância de adornos de ossos. A quantidade de adornos por criança também foi recorrente: predomínio de apenas um adorno por sepultamento. No período antigo há uma criança que apresenta como adorno três (3) contas de amazonita com perfurações no centro. Por sua vez, há diferenças nos adornos do período intermediário com a presença de mais de um colar. Com idade de 4 a 6 anos uma criança apresentava cinco (5) contas de colar de osso de animais, quantidade não encontrada nos outros sepultamentos, assim como outra com idade entre 6 a 8 anos apresenta contas de colar de ossos e um pingente de dente de felino, podendo significar um status social diferenciado ou diferenças marcadas pela idade.

Binford (1971) foi um dos primeiros a afirmar que o social está presente na cultura material das sepulturas. Para este autor, os artefatos são parte do sistema cultural humano; assim, o tratamento dispensado ao morto, sua posição na sepultura e os materiais presentes são utilizados para indicar a posição social e 
econômica do indivíduo. Complementando essas ideias, Saxe (1970), afirma que os dados mortuários podem ser utilizados para fazer inferências sociais. Assim, no estudo das práticas funerárias as diferenças entre sociedades estariam refletidas nos acompanhamentos funerários.

Contrariamente, Tainter (1978) chama a atenção para o fato de que nem sempre a presença de um determinado material indicaria uma situação de status; propõe observar também a condição de ausência de determinado material relacionado à idade e ao sexo. A identificação do sexo e da idade dos indivíduos pode permitir inferências sobre os papéis sociais atribuídos a cada gênero. O’Shea (1984) destaca a importância do sexo e da idade, considera-os referenciais primários. Em toda sociedade os indivíduos são, inicialmente, divididos pelo sexo e pela idade. É a primeira identidade a ser atribuída a um indivíduo. Por isso esses dois elementos são importantes na identificação de identidades.

Em trabalhos de arqueologia há exemplos da ligação entre o uso de certos objetos (como adornos e instrumentos de trabalho), a posição do corpo na sepultura; ou do tipo de sepultamento com o sexo, a idade ou a situação ou status do indivíduo no grupo social.

Em relação às diferenças baseadas no sexo, na Furna do Estrago nossos resultados não indicam uma diferenciação. Contudo, no estudo realizado por Lima (2012) direcionado especificamente para os papéis de gênero, atribuídos a homens e 
mulheres, no contexto funerário dos sítios Justino e Furna do Estrago, foi possível verificar algumas diferenças. A autora evidencia no sítio Furna do Estrago que as sepulturas apresentam profundidade com variação entre $40 \mathrm{~cm}$ a $100 \mathrm{~cm}$ da superfície; em sua maioria com a forma circular (em 33 sepulturas de homens e mulheres). Contudo, há apenas dois casos de sepulturas estruturadas por blocos de rocha e nestes os indivíduos são masculinos. Seus resultados indicam a presença de identidades de gênero representadas por meio de objetos presentes nas sepulturas e em lesões dentárias associadas diferentemente aos homens e às mulheres e decorrentes de uma alimentação diferenciada e de atividades de trabalho relacionada com o uso dos dentes. Foi verificado que as mulheres apresentavam variedade de matéria-prima nos colares, como a presença de contas feitas de ossos, conchas e dentes. Ao passo que, nos homens foi verificado o predomínio de colares com contas de material ósseo com morfologia cilíndrica ou anelada, e também contas feitas de concha no formato de pequenos discos. Algumas variáveis são associadas exclusivamente aos homens: sepultamentos secundários, o decúbito dorsal, instrumentos de madeira e osso, instrumentos musicais. Contudo, não há diferenças entre homens e mulheres em relação à posição do corpo, a lateralidade e a flexão dos membros superiores e inferiores.

Por sua vez, Sene (2007) estudou 23 estruturas funerárias do sítio arqueológico Gruta do Gentio II, localizado no município de Unaí, Minas Gerais, e buscou analisar indicadores de gênero e de diferenciação social no contexto funerário. Definiu indicadores tanto biológicos como da cultura material. Os indivíduos 
femininos, alguns adolescentes e crianças estão vinculados ao uso de objetos pessoais. São colares e pulseiras de contas de sementes de gramíneas e pingentes de bivalves de água doce e de pedra. Já nos indivíduos masculinos, jovens, adultos e maduros, além de raras crianças, foi recorrente a associação com o couro, cordéis de fibras vegetais, pingentes de sementes perfuradas e adornos labiais.

Aos indivíduos de ambos os sexos e de diferentes faixas etárias, estão associados o uso de penas e pigmentos vermelhos. Contudo, observou-se uma maior associação dos pigmentos vermelhos aos homens e crianças, e as penas às mulheres. Em relação à posição do corpo na sepultura, a autora também identificou que havia relação com o sexo. Os corpos foram arrumados e depositados de forma diferenciada em função do sexo. As posições mais frequentes para a deposição dos corpos foram decúbito dorsal e decúbito lateral, com membros inferiores fortemente fletidos. Nas mulheres há indicativo de recorrência de semiflexão, ao contrário dos homens, que foram extremamente amarrados e hiperflexionados. Os homens foram depositados em fardos de couro de cervídeos, enquanto as mulheres e as crianças foram colocadas em esteiras de buriti. Percebemos assim, que nos sepultamentos estudados por Sene é possível confirmar a presença de marcadores de identidades representados pela faixa etária, pelo gênero, pela posição do corpo e pelos acompanhamentos funerários.

Em outro trabalho, Schaan (2001) fez um estudo de caso sobre as estatuetas antropomorfas da cultura Marajoara. Argumentou que as estatuetas deviam ser 
entendidas como objetos simbólicos ligados a discursos contextuais de identidade social e de gênero. As estatuetas representariam marcadores de identidades de gênero. A fase Marajoara se caracteriza pelo predomínio de representação de figuras femininas em estatuetas e urnas funerárias, o que implica na construção de visões que envolvem aspectos relativos aos papéis sociais e políticos de mulheres em cerimônias e rituais, e consequentemente, em estruturas de poder. As figuras antropomorfas femininas são identificadas pela representação de seios, triângulos pubianos e, em alguns casos, com ventres avolumados.

A questão de gênero e identidade ultrapassa, para Schaan (2001), o nível do sexo biologicamente definido. Os contextos sociais são organizados em função das relações de poder (masculino X feminino), da produção econômica, entre outros. Entretanto, outros aspectos podem ser relevantes, em função da idade e de atividades especializadas. A autora argumenta que, em muitas sociedades, crianças são tratadas como seres que não são nem femininos nem masculinos e só adquirem identidade de gênero e papéis sociais quando são iniciados nos rituais de passagem. Assim, também, em algumas sociedades mulheres mais velhas passam a ter o direito de participar de ritos cerimoniais restritos ao homem, e proibidos a mulheres em idade reprodutiva.

Em relação a diferenças nos sepultamentos de crianças, Lucy (1994, apud Lucy, 2005) avaliou as atitudes sociais no tratamento funerário de crianças em cemitérios cristãos e pré-cristãos em Yorkshire, Inglaterra, entre os séculos V e 
XII. Seu estudo demonstrou que, nos cemitérios cristãos, a distinção entre crianças e adultos era feita pela localização dos corpos no espaço em torno da igreja. Já nos cemitérios pré-cristãos a distinção entre adultos e crianças foi observada na posição dos bens que acompanhavam as sepulturas e no número de sepultamentos de crianças em posição flexionada ou agachada. A autora interpretou que, nos cemitérios pré-cristãos, para caracterizar o que era uma criança e o que era um adulto alguns fatores tinham mais peso que a idade cronológica. A distinção nos cemitérios cristãos foi interpretada como uma noção mais rígida do papel da criança nas sociedades cristãs. Lucy conclui que os grupos etários estão subordinados às noções dos papéis sociais em diferentes tempos históricos, determinados por cada sociedade para os seus membros. Neste caso, os marcadores de identidade na sociedade pré-cristã estariam representados na diferença entre adultos e crianças através da posição dos objetos presentes nas sepulturas e na posição dos corpos das crianças, agachadas e com membros flexionados.

$\mathrm{Na}$ Furna do Estrago, os envoltórios de fibras vegetais representariam elementos de uma identidade coletiva, algo que identifica a prática funerária destes indivíduos. Este tipo de envoltório pode ser encontrado em outros sítios arqueológicos, associados a sepultamentos. Há informações, nas descrições da etnografia e da etnohistória, sobre o uso de redes e de cordas nas quais os mortos eram envolvidos antes de serem colocados dentro das covas. Podemos citar Lery (1980), Soares de Sousa (2000) e Carneiro da Cunha (1978). 
Entre os Krahó, na prática do sepultamento secundário, após o descarne, os ossos eram pintados de urucu, embrulhados em uma esteira e enterrados em uma cova funda; esta prática, contudo, dependia do status do morto e era proibida às crianças (Carneiro da Cunha, 1978).

Nos trabalhos arqueológicos, podemos citar Oliveira (2001) e Maranca (1991). Ao escavar o sítio Alcobaça, Oliveira (2001) identificou o uso de restos de trançados de fibras vegetais nos cinco sepultamentos secundários e coletivos identificados nestes sítios. Além dos trançados, foram identificados fios de cordéis elaborados com fibras de palmeira e de cordas produzidas em fibras de caroá. Estes sepultamentos estão datados entre $2466 \pm 26$ AP e $1873 \pm 24$ AP. Em outro sítio, Toca do Congo I, localizado no PARNA Serra da Capivara, no sudeste do Piauí, existia vestígios de envoltórios, provavelmente restos de tecidos ou de redes associados aos sepultamentos depositados em fossas escavadas no solo do abrigo. Estes sepultamentos estão datados em $2090 \pm 110$ anos BP (Maranca, 1991).

Nestes sítios, assim como na Furna do Estrago, as fibras vegetais e as cordas foram elementos recorrentes da prática funerária. No trabalho realizado por Menezes (2006) sobre os macrorrestos vegetais identificados no sítio Furna do Estrago. O resultado revelou a presença de fibras e sementes. Ficou constatado que as sementes foram utilizadas como contas de colares e pingentes e foram encontradas em seis indivíduos adultos. Além de sementes, foram identificadas 
fibras de caroá, utilizadas nos cordéis e esteiras confeccionados de fibras de palmeira, associados aos contextos funerários. Menezes concluiu que o material vegetal desempenhou um importante papel na vida cotidiana dos grupos da Furna do Estrago, fato sugerido pelo desgaste dentário verificado por Rodrigues (1997), indicando o uso dos dentes em atividades de produção, como a confecção de esteiras e trançados, bem como na própria alimentação.

\section{CONSIDERAÇÕES FINAIS}

Realizar o sepultamento primário fazia parte do ritual funerário destes indivíduos. Verificamos que a deposição do corpo na sepultura estava relacionada com a idade. Para os adultos e adolescentes (>12-20a) a recorrência era ser inumado em decúbito lateral, não importando para que lado, ou seja, para os adolescentes suas identidades estariam mais próximas dos adultos. A maioria das crianças (0-12a) foi depositada em decúbito dorsal.

Como parte do ritual houve a colocação de adornos como acompanhamento funerário. Tanto nas crianças como nos adultos foram utilizados colares de contas de osso, de amazonita e de concha. Os colares de osso foram os mais recorrentes em todas as idades. Porém, nas crianças e nos adolescentes não havia adornos de sementes; esses foram utilizados em três indivíduos adultos da ocupação intermediária. De forma semelhante os adornos de contas de amazonita não foram de uso coletivo, o que pode sugerir que este material era restrito a alguns indivíduos adultos e infantis. 
Quanto à representação material de identidades no contexto funerário para este sítio identificamos os colares e as fibras vegetais como elementos de uma identidade coletiva, pois são recorrentes na maioria dos indivíduos enterrados; apesar do número de variáveis indeterminadas, constatamos recorrência no tipo de sepultamento, no uso de envoltório de fibras vegetais, no uso de adornos e na maneira de depositar o morto na cova. Além desses objetos como marcadores de identidades coletivas argumentamos que existem elementos indicadores de identidades baseadas na idade. Adultos e crianças foram depositados, de forma diferenciada, em função de suas idades. A idade, portanto, não é apenas uma categoria biológica, mas construída culturalmente e está relacionada com o papel atribuído a cada indivíduo dentro de seu grupo social.

Esses elementos recorrentes são indicativos de semelhanças no ritual funerário. Ainda que os resultados sejam parciais, os dados por nós analisados permitem afirmar que há mais elementos semelhantes entre as três ocupações do que diferenças. E este é um forte indicador de persistência de identidades coletivas. Entretanto, percebemos que os contextos das escavações não concorreram para uma avaliação mais aprofundada dos elementos de identidade. A falta de dados uniformes, ausentes, ou de categorias indeterminadas não permitiu um melhor aproveitamento das informações disponíveis na identificação de identidades.

Considerando os motivos expostos, reconhecemos que este trabalho poderá contribuir, em um campo ainda pouco explorado pelos arqueólogos no Brasil, na 
discussão dos traços, ainda que parciais, de identidades representadas na materialidade das estruturas funerárias; como também no entendimento dos fatores que levaram às diferenciações percebidas nos sepultamentos.

\section{REFERÊNCIAS BIBLIOGRÁFICAS}

ALENCAR, R. Caracterização Bioarqueológica dos Ossos Provenientes da Furna do Nego, Jataúba, Pernambuco: análise qualitativa e quantitativa dos dados demográficos. 2013. Monografia, Bacharelado em Arqueologia, Universidade Federal de Pernambuco, Recife, 2013.

. Estudos osteoarqueológicos das remodelações articulares nos adultos jovens inumados no cemitério pré-histórico da Furna do Estrago, Brejo da Madre de Deus, PE. 2015. Dissertação, Mestrado em Arqueologia, Universidade Federal de Pernambuco, Recife, 2015.

BINFORD, L. R. Mortuary practices: their study and their potential. In: BROWN, J. A. (Ed.). Approaches to the social dimensions of mortuary practices. Memoirs of the American Archaeology Society, (25), 6-29. 1971.

CARNEIRO DA CUNHA, M. Os mortos e os outros: uma análise do sistema funerário e da noção de pessoa entre os índios Krahó. São Paulo: Hucitec. 1978.

CARVALHO, O. A. Espodilólise e variações morfológicas congênitas identificadas na população pré-histórica do sítio Furna do Estrago, Pernambuco. Symposium, Recife, v. 34, (2), 180 -195, jul./dez. 1992.

Análise das anomalias de desenvolvimento na população pré-histórica do sítio Furna do Estrago, Pernambuco, Brasil. 1995, Dissertação, Mestrado em Saúde Pública, Escola Nacional de Saúde Publica/ Fundação Oswaldo Cruz, Rio de Janeiro, 1995.

CARVALHO, O. A.; QUEIROZ, A. N.; MORAES, F. A. Diagnóstico diferencial entre fatores tafonomicos, anomalias de desenvolvimento e casos patológicos nos crânios exumados do sitio Furna do Estrago, Brejo da Madre de Deus, Pernambuco, Brasil. Canindé, Aracaju, (10), 27-49. 2007. 
CASTRO, V. M. C. O uso do conceito de identidade na arqueologia. Clio, Recife, v.1, (23), 170-188 (Série Arqueológica). 2008.

Marcadores de identidades coletivas no contexto funerário pré-histórico no Nordeste do Brasil. 2009. Tese, Doutorado em Arqueologia, Universidade Federal de Pernambuco, Recife, 2009.

D’EVREUX, Y. Viagem ao norte do Brasil: feita nos anos de 1613 a 1614. São Paulo: Siciliano. 2002.

DUARTE, A. N. Estudo paleoparasitológico em coprólitos do sítio arqueológico Furna do Estrago, município do Brejo da Madre de Deus, Pernambuco. 1994, Dissertação, Mestrado em Ciências Biológicas, Universidade Federal Rural do Rio de Janeiro, Rio de Janeiro, 1994.

JORGE, S. O. In: JORGE, V. O. et al. (Coord.) Identidade, identidades. Porto: Adecap. 2002.

LÉRY, J. Viagem à terra do Brasil. Belo Horizonte: Itatiaia (Reconquista do Brasil, 10). 1980.

LIMA, D. V. R. Sobre morte e gênero: uma análise dos papeis de gênero no contexto funerário dos sítios Justino - SE e Furna do Estrago - PE. 2012, Dissertação, Mestrado em Arqueologia, Programa de Pós-Graduação em Arqueologia, Universidade Federal de Pernambuco, Recife, 2012.

LIMA, J. M. Pesquisa arqueológica no município do Brejo da Madre de Deus Pernambuco. Symposium, Recife, v. 26 (1), 9-60. 1984a.

. Arqueologia do Brejo da Madre de Deus, Pernambuco. Clio, Recife, (6), 91-94 (Arqueológica, 1). 1984b.

Arqueologia da Furna do Estrago, Brejo da Madre de Deus - Pernambuco. Dissertação, Mestrado em Antropologia Cultural, Programa em Pós-Graduação em Antropologia, Universidade Federal de Pernambuco, Recife. 1985a.

Arqueologia da Furna do Estrago, Brejo da Madre de Deus - PE. Clio, Recife, (7), 97-111 (Arqueológica, 2). 1985b. 
El sitio arqueológico Furna do Estrago - Brasil: Em uma perspectiva antropológica y social. Tesis, Doctorado en Antropología, Facultad de Filosofia y Letras, Universidad Nacional Autônoma de Mexico, Mexico, 2001.

LUCY, S. The archaeology of age. In: DÍAZ-ANDREU, M. et al. The Archaeology of identity. New York: Routledge, 43-66. 2005.

LUKESCH, A. Mito e vida dos índios Caiapós. São Paulo: Pioneira, 1976.

MARANCA, S. Agricultores e ceramistas da área de São Raimundo Nonato, Piauí. Clio, Recife, v.1 (4) (extra), 95-96 (Série Arqueológica). 1991.

MARTIN, G. Pré-História do Nordeste do Brasil. 4. ed. Recife: Editora Universitária, UFPE.2005.

MELLO E ALVIM, M. C.; MENDONÇA DE SOUZA, S. Os esqueletos humanos da Furna do Estrago - Pernambuco, Brasil - Nota prévia. Arquivos do Museu de História Natural, Belo Horizonte, v. 8-9, 349-363. 1983-1984.

MENDONÇA DE SOUZA, S. Traumatismos vertebrais como indicadores de atividade física na população da Furna do Estrago, Pernambuco. In: ARAÚJO, A. J. G.; FERREIRA, L. F. (Orgs.) Paleopatologia e Paleoepidemiologia: estudos multidisciplinares. Rio de Janeiro: Escola Nacional de Saúde Publica/ Fundação Oswaldo Cruz, 123-139 (Panorama ENSP, 4). 1992.

MENDONÇA DE SOUZA, S.; MELLO E ALVIM, M. A população pré-histórica da Furna do Estrago: adaptação humana ao Agreste pernambucano. Symposium, Recife, v. 34, (2), 123-145, jul./dez. 1992.

MENDONÇA DE SOUZA, S. Estresse, doença e adaptabilidade: estudo comparativo de dois grupos pré-históricos em perspectiva biocultural. Tese, 1995, Doutorado em Saúde Pública, Escola Nacional de Saúde Publica/ Fundação Oswaldo Cruz, Rio de Janeiro, 1995.

MENEZES, A. V. A. Estudo dos macro-restos vegetais do sítio arqueológico Furna do Estrago, Brejo da Madre de Deus, Pernambuco, Brasil. 2006, Dissertação, Mestrado em 
Arqueologia, Programa de Pós-Graduação em Arqueologia, Universidade Federal de Pernambuco, Recife. 2006.

OLIVEIRA. M. M. B. M. Práticas funerárias pré-históricas infantis do sítio Furna do Estrago, PE. Trabalho de Conclusão de Curso, Bacharelado em Arqueologia, Universidade Federal de Pernambuco. 2014.

Análise macroscópica das alterações no esmalte dentário e dieta dos indivíduos subadultos enterrados no sítio arqueológico Furna do Estrago, PE. 2018, Dissertação, Mestrado em Arqueologia, Programa de Pós-Graduação em Arqueologia, Universidade Federal de Pernambuco, Recife. 2018.

OLIVEIRA, A. L. N. O sítio arqueológico Alcobaça: Buíque, Pernambuco- estudo das estruturas arqueológicas. 2001, Tese, Doutorado em História, Programa de PósGraduação em História, Universidade Federal de Pernambuco, Recife, 2001.

O'SHEA, J. Mortuary variability: an archaeological investigation. New York: Academic Press (Studies in Archaeology). 1984.

RODRIGUES, C. D. Perfil dento-patológico nos remanescentes esqueletais de dois sítios pré-históricos brasileiros: o cemitério da Furna do Estrago (PE) e o sambaqui de Cabeçuda (SC). 1997, Dissertação, Mestrado em Saúde Pública, Escola Nacional de Saúde Publica/ Fundação Oswaldo Cruz, Rio de Janeiro. 1997.

SANTOS, M. S. Memória coletiva e teoria social. São Paulo: Annablume. 2003.

SAXE, A. A. Social dimensions of mortuary practices. Tese (PhD), University of Michigan: Ann Arbor. 1970.

SCHAAN, D. P. Estatuetas antropomorfas Marajoara: o simbolismo de identidades de gênero em uma sociedade complexa Amazônica. Boletim do Museu paraense Emílio Goeldi, Belém, v. 17 (2), 437 - 477 (Série Antropologia). 2001.

SCHMITZ, P. I.; SOUZA, S. M. F. M.; BEBER, M. V. A Furna do Estrago no Brejo da Madre de Deus, PE. Antropologia, (69), 2012.

SENE, G. A. M. Indicadores de gênero na pré-história brasileira: contexto funerário, simbolismo e diferenciação social. O sítio arqueológico Gruta do Gentio II, Unaí, Minas 
Gerais. 2007, Tese, Doutorado em Arqueologia, Museu de Arqueologia e Etnologia, Faculdade de Filosofia, Letras e Ciências Humanas, Universidade de São Paulo, São Paulo, 2007.

SHENNAN, S. J. Quantifying Archaeology. 2.ed. Edinburgh University Press.1997.

SILVA, R. A. P. Acompanhamentos funerários como marcadores culturais do sítio préhistórico Furna do Estrago - PE. 2016. Trabalho de Conclusão de Curso, Bacharelado em Arqueologia, Universidade Federal de Pernambuco, Recife, 2016.

SILVA, S. F. S. M. Arqueologia funerária: corpo, cultura e sociedade: Ensaios sobre interdisciplinaridade arqueológica no estudo das práticas mortuárias. Recife: PROEXTUFPE/Editora Universitária da UFPE, 2014. (Série Extensão).

.Terminologias e classificações usadas para descrever sepultamentos humanos: exemplos e sugestões. Revista do Museu de Arqueologia e Etnologia, São Paulo, (15-16), 113-138. 2005/2006.

SILVA, T. T. A produção social da identidade e da diferença. In: SILVA, Tomaz T. (Org.). Identidade e diferença - A perspectiva dos estudos culturais. Petrópolis: Vozes, 73-102. 2005.

SOUSA, G. S. Tratado descritivo do Brasil em 1587. 9 ed. Recife: Massangana. (Série Descobrimentos, 13). 2000.

THEVET, A. As singularidades da França antártica. São Paulo: Editora da USP. 1978.

VIDAL, L.; SILVA, A. L. O Sistema de objetos nas sociedades indígenas: arte e cultura material. In: SILVA, A.; GRUPIONI, L. (Orgs.) A Temática Indígena na Escola: Novos subsídios para professores de $1^{\circ}$ e $2^{\circ}$ graus. 3 ed. São Paulo: Global, 369-402. 2000.

WOODWARD, K. Identidade e diferença: uma introdução teórica e conceitual. In: SILVA, Tomaz T. (Org.) Identidade e diferença - A perspectiva dos estudos culturais. Petrópolis: Vozes, 7-72. 2005.

WHITE, T. D.; BLACK, M. T.; FOLKENS, P. A. Human Osteology. San Diego: Elsevier, 2012. 